\title{
A SOCIALIZAÇÃO POLÍTICA DOS ESTUDANTES NO PLURAL*
}

\author{
Pedro Caetano ${ }^{1}$
}

\begin{abstract}
RESUMO: No âmbito da socialização política e moral, estudos recentes têm vindo a descentrar-se da problemática da integração e a interessar-se pelas diferentes formas de fazer emergir o comum, segundo as diferentes gramáticas políticas e a partir da variabilidade dos contextos. Com o objetivo de conhecer o modo como os estudantes do ensino médio público português contribuem para fazer emergir o comum sob os constrangimentos da instituiçáo escolar, aplicamos um questionário por cenários a 725 estudantes de 3 escolas da Grande Lisboa. Os resultados da análise sugerem que os estudantes mobilizam diferentes gramáticas políticas em situação, mostrando envolvimentos qualitativamente contrastados. Os resultados mostram ainda a grande vulnerabilidade dos estudantes nessas situações e os seus efeitos.
\end{abstract}

Palavras-chave: Socialização política. Estudantes. Questionário por cenários. Vulnerabilidade. Grande Lisboa.

\section{THE POLITICAL SOCIALIZATION OF STUDENTS IN THE PLURAL}

ABSTRACT: In the context of political and moral socialization, recent studies have been gradually decentering from the integration models issue to concentrate itself in the different ways to bring out the common, according to the different political grammars and from the variability of contexts. To find out how the students of the Portuguese public school contribute to bring out the common under the constraints of the educational institution, we applied a scenariosbased questionnaire to 725 students from 3 schools in the Greater Lisbon. The findings of analysis suggest that students mobilize different political grammars according to the situation, showing qualitatively contrasted engagements. The results still indicate the great vulnerability of students in these situations and their effects.

Keywords: Political socialization. High school students. Scenario-based questionnaire. Vulnerability. Greater Lisbon.

\footnotetext{
*O presente artigo é produto de uma investigação intitulada "Individuação e reconhecimento: processos de socialização política na incerteza dos itinerários escolares”, desenvolvida entre 2009 e 2013, ao abrigo de uma Bolsa de Doutoramento da Fundaçáo para a Ciência e Tecnologia, de Portugal.

${ }^{1}$ Universidade Nova de Lisboa, Faculdade de Ciências Sociais e Humanas, Centro Interdisciplinar de Ciências Sociais - Lisboa (Portugal). E-mail: caepedro@gmail.com

DOI: 10.1590/ES0101-73302016165913
} 


\title{
LA SOCIALISATION POLITIQUE DES LYCÉENS AU PLURIEL
}

\begin{abstract}
RÉSUMÉ: Dans le contexte de la socialisation politique et morale, des études récentes ont été progressivement décentrées de la question des modèles d'intégration pour se concentrer sur les différentes façons de faire ressortir le commun, selon les différentes grammaires politiques et à partir de la variabilité des contextes. Afin de savoir comment les élèves de l'école publique portugaise contribuent pour faire ressortir le commun sous les contraintes de l'institution scolaire, nous avons appliqué un questionnaire pour scénarios à 725 étudiants de 3 écoles de la Grande Lisbonne. Les résultats de l'analyse indiquent que les lycéens mobilisent de différentes grammaires politiques selon la situation, en montrant des engagements qualitativement contrastés. Les résultats révèlent encore la grande vulnérabilité des élèves dans ces situations et leurs effets.
\end{abstract}

Mots-clés: Socialization politique. Lycéens. Questionnaire pour scenários. Vulnerabilité. Grande Lisbonne.

\section{Introdução}

A

socialização política dos mais jovens tem vindo a constituir-se como um dos grandes desafios deste início de século nos países mais industrializados deste lado do Atlântico (GIBSON; LEVINE, 2003; RESENDE, 2010), ou do outro lado do mesmo (O'NEILL, 2007; USDE, 2012). Esse desafio estende-se inclusivamente ao espaço transnacional representado pela União Europeia que, mormente por meio do Programa Eurydice (EC, 2016), pretende promover uma Europa dos Cidadãos baseada nos valores da democracia, da solidariedade e da interculturalidade, entre outros. No cerne das preocupaçóes dessas iniciativas, encontra-se fundamentalmente a baixa participação eleitoral dos jovens, mas também a necessidade sentida de fomentar um espaço de vivência e de experiência, segundo determinados valores e regras comuns. A concretização desse espaço comum, porém, poderá ser levada a cabo segundo diferentes perspectivas normativas: uma perspectiva em que o comum precede os agentes - perspectiva clássica da socialização política -, ou uma perspectiva na qual a comunidade política, com os seus membros interagindo e partilhando significados nos seus ambientes de vida, vai emergindo pouco a pouco dos seus meios associativos. Nessa última, os modelos de integraçáo perdem a sua primazia na socialização política em benefício de outras gramáticas políticas mobilizadas pelos atores. Desse modo, a mudança não é necessariamente vista como negativa, mas como uma evolução tática decorrente do trabalho dos atores nos seus modos de fabricar o comum. 
Essa diferente forma de encarar a fabricação do comum sugere, em todo o caso, uma perspectiva mais analítica dos processos de socialização política, a qual procura reconhecer e demonstrar a existência de uma visão multidimensional da socialização política, onde essa apresenta vários níveis ou camadas (EKMAN; AMNÅ, 2012) ou constitui-se por meio de "um delicado balanceamento entre a ordem e a desordem, o controlo e a vulnerabilidade" (NUSSBAUM, 2001, p. 81).

De um ponto de vista normativo, com o intuito de colocar à prova a multidimensionalidade dos processos de socialização política e com o objetivo de conhecer o modo como os estudantes do ensino secundário português contribuem para fazer emergir o comum sob os constrangimentos da instituição escolar, aplicamos um questionário por cenários a 725 estudantes de 3 escolas da Grande Lisboa. Os resultados da análise sugerem que os estudantes mobilizam diferentes gramáticas políticas em situação e, como tal, mostram envolvimentos qualitativamente contrastados relativamente às regras escolares.

\section{A multidimensionalidade dos processos de socialização política}

Já na Antiga Grécia, o carácter normativo da socialização política achou-se notavelmente explorado, objeto privilegiado que foi, durante a curta história da democracia ateniense, de perspícuas disputas entre alguns dos seus mais ilustres cidadãos-filósofos: Protágoras, Sócrates, Platão, Aristóteles. Com efeito, os dois primeiros, segundo Nussbaum (2001) na sua extraordinária obra datada de 1986, The Fragility of Goodness, emergem como formidáveis adversários do domínio incontestado que a fortuna exercia na vida social e política dos atenienses. A fatalidade, o destino, a sorte, popularizadas nas tragédias gregas e subsumidas no conceito de tuché, "não implicam aleatoriedade ou ausência de conexóes causais. $\mathrm{O}$ seu significado básico é 'o que acontece simplesmente'; é o elemento da existência humana que os seres humanos não controlam" (NUSSBAUM, 2001, p. 89). Frente a essa exposição à fortuna, começa a despontar outra concepção - a techné caracterizada fundamentalmente pelo "juízo prático ou sabedoria com recurso à prospecção, ao planejamento e à predição" (NUSSBAUM, 2001, p. 95). A techné como forma de controlar a tuché, de "gerir a necessidade por meio da predição e controle sobre as contingências futuras" (NUSSBAUM, 2001, p. 95); a techné como forma tipicamente moderna de relação humana com o mundo.

Contudo, Protágoras e Sócrates não partilhavam as mesmas concepções normativas sobre a racionalidade prática dos atores, defendendo formas de techné bem distintas: "Protágoras, conservador e humanista, quer uma techné que fica perto da prática ordinária de deliberação, sistematizá-la apenas um pouco" (NUSSBAUM, 2001, p. 99), ao passo que Sócrates, 
[...] mais profundamente dominado pela urgência dos problemas práticos do homem, considerava tal insuficiente. Temos de ir mais longe, ser inteiramente científicos, se quisermos "salvar as nossas vidas" — mesmo que a ciência faça dessas vidas salvas vidas bem diferentes (NUSSBAUM, 2001, p. 99).

A atenção que ambos reservaram ao problema da medida, na verdade, implicou caminhos e resoluções contrários: Protágoras, célebre pela máxima que lhe é atribuída de "o Homem como medida de todas as coisas", confiava na argumentação e na deliberação política de cidadãos razoáveis como o método privilegiado de enfrentar a exposição à fortuna; Sócrates, por seu turno, reivindicando uma verdade precisa e absoluta, desconfiava da validade dos juízos morais ordinários e pugnava pelo instrumentalismo de controle científico.

De acordo com Nussbaum (2001, p. 100), no entanto, tanto Protágoras como Sócrates incorrem, cada um com o seu método, na tentativa de comensuração dos valores, suprimindo uns em detrimento de outros, hierarquizando-os, uniformizando-os; em todo o caso, reduzindo, e desse modo empobrecendo, a pluralidade dos valores existentes, seja em nome da boa deliberação (Protágoras) ou da precisão (Sócrates). Nesse sentido, os efeitos da techné, propondo outras garantias contra os ventos da fortuna e fazendo sublinhar no processo os critérios de universalidade, de aprendizagem e de preocupação com a explicação, acabam por alterar irremediavelmente a natureza das nossas vulnerabilidades (NUSSBAUM, 2001, p. 121).

Não obstante, Platão, discípulo de Sócrates e face aos problemas do seu tempo, irá desenvolver substancialmente as ideias de Sócrates, transformando o método socrático no método platónico e, por essa via, reconstruindo uma nova forma de techné. Platão, na sua preocupação com a estabilidade dos valores e minimização do potencial de conflito entre os mesmos, definiu "um ponto de vista de perfeição para determinar um valor estético/moral, construindo para os jovens cidadãos, um discurso, uma representação deste ponto de vista como um ideal moral" (NUSSBAUM, 2001, p. 158). Assim, "devemos imitar os seres que estão acima das necessidades e interesses meramente humanos, a fim de cultivar o nosso próprio potencial para a racionalidade objetiva" (NUSSBAUM, 2001, p. 158).

Reconhecemos assim, na reelaboração da techné platónica, os pressupostos de edificação da socialização política republicana. Os valores verdadeiros caracterizam-se essencialmente pela pureza e universalidade, em uma judiciosa harmonia e imparcialidade. $\mathrm{O}$ educando, familiarizando-se com esses valores, mormente pela contemplação, poderá subsequentemente ascender a estados mais elevados de grandeza cívica através do conhecimento. 
Objetando tanto a techné platônica como a sua ideia-guia sugerida pelo eidos, Aristóteles recusa a universalidade e intelectualismo platônico, uma vez que:

[...] se dermos prioridade ao geral perde-se o valor ético da surpresa, contextualidade e particularidade. Abstrair o intelecto prático das paixóes equivale a perder não apenas o seu poder de motivar e informar, mas também o seu intrínseco valor humano (NUSSBAUM, 2001, p. 310).

Para Aristóteles, o método privilegiado reside no poder de julgamento individual, mormente nas suas capacidades perceptivas, face à variabilidade das situaçôes em que se vê confrontado, sempre incertas, ambivalentes e indeterminadas. De posse unicamente de uma perspectiva científica e técnica, o indivíduo ficaria aquém da "responsividade e flexibilidade necessárias para produzir uma correção do 'tom' e uma segurança de toque que não podem ser adequadamente capturados por uma qualquer descrição geral" (NUSSBAUM, 2001, p. 304). O mesmo é dizer que, contra a perspectiva sistêmico-estratégica da socialização política platónica, Aristóteles apresenta-nos como solução uma perspectiva declaradamente tática (DE CERTEAU, 1988).

É nesse quadro que, recuperando a concepção normativa aristotélica e contra a supremacia da concepção técnica da socialização política, Carr e Kemis (1986, p. 25) criticam o processo educativo encarado como uma maisvalia, no qual:

[...] a tarefa do professor consiste em criar sistemas de transmissão de conteúdos que são "justos" (fair) no sentido burocrático do termo; quer dizer, que proporcionam livre acesso a todos e tratam os indivíduos independentemente dos seus interesses e idiossincrasias, com base apenas na performance (CARR; KEMIS, 1986, p. 25).

Para esses autores, à prática educativa não deve ser assimilada apenas uma questáo de treino ou de indoutrinação (CARR; KEMIS, 1986, p. 38), mas "uma direção flexível e espontânea da aprendizagem, guiada por uma observação sensitiva às mudanças subtis e às respostas dos outros participantes no processo" (CARR; KEMIS, 1986, p. 37). Nesse sentido, os objetivos da educação não devem ser subsumidos quer à techné platônica, quer à techné socrática, a primeira excessivamente centrada na obediência e no intelectualismo, a segunda no desempenho e na aquisição de competências, como métodos privilegiados de controle do processo educativo. 
Ora a socialização política no sistema educativo português tem-se caracterizado fundamentalmente, desde a sua implementação sistemática sob a forma de uma área náo curricular de Educaçáo para a Cidadania, em 2001, pela ação de três aspetos cruciais: a influência da União Europeia, mormente a dimensão europeia da educação; a fragmentação dos conteúdos a trabalhar na escola; e uma excessiva ênfase na dimensão instrutória da educação para a política.

A dimensão instrutória tem sido reforçada nos últimos anos com a introdução de novas disciplinas e áreas disciplinares no seu currículo oficial. Primeiramente, com a implementação da disciplina de Educação para a Cidadania, em 2001, no $2^{\circ}$ e $3^{\circ}$ ciclos do ensino básico (dos 10 aos 14 anos) e, a partir de 2004, com a área disciplinar transversal de Educação para a Cidadania no ensino secundário regular (correspondente ao ensino médio no Brasil). A última novidade nesse âmbito ocorreu em 2006, com a homologação da disciplina opcional de Ciência Política no $12^{\circ}$ ano de escolaridade na componente de Formação Específica dos Cursos Científico-Humanísticos. Essa disciplina, como se pode ler na introdução dos autores do programa curricular, tem a "finalidade de dotar os jovens de instrumentos que possibilitem uma análise crítica do mundo, promovendo a sua participação ativa e informada na sociedade" (MOREIRA; ROSAS; LOBO, 2006, p. 3).

A fragmentação do currículo encontra-se bem patente nas linhas orientadoras do Ministério da Educação (DGE, 2013), em que a Educação para a Cidadania aparece espartilhada por 14 objetos diferentes: desde a Educação Rodoviária, passando pela Educação Financeira, a Educação para o Empreendedorismo, a Educação para a Saúde e a Sexualidade, a Educação para os Direitos Humanos, a Dimensão Europeia da Educação, até a Educação Intercultural, entre outras.

A influência da União Europeia (UE) pode ser vista quer na decisiva implementação da área não curricular da Educaçáo para a Cidadania (RIBEIRO; NEVES; MENEZES, 2014), quer no destaque que a Dimensão Europeia da Educaçáo tem adquirido no currículo. Na verdade, pode ler-se no referencial divulgado nas escolas:

[...] se, no início, o conceito de dimensão europeia se centrava no conhecimento que alunos e professores deveriam ter sobre os Estados-membros, atualmente, o conceito implica náo só o conhecimento, mas o exercício de uma cidadania europeia ativa (DGE, 2015, p. 9).

Reconhecendo a preponderância da techné platónica, a UE solicita um outro regime de envolvimento na escola, um envolvimento segundo a perspectiva da mais valia que, de resto, encontra-se presente desde sempre em sua matriz (CCE, 1993). Esse regime de envolvimento (THÉVENOT, 2006) fica bem expresso nestas palavras: que os estudantes têm de estar "preparados para enfrentar 
os desafios do mundo global, tirando partido das vantagens da UE, adquirindo conhecimentos e capacidades e desenvolvendo competências adequadas às exigências do mercado de trabalho" (DGE, 2015, p. 9).

As diferentes dimensões da socialização política, consubstanciadas nas suas várias concepçóes normativas e regimes de envolvimento, constituem um campo de análise suscetível de contribuir heuristicamente para o estudo dos processos de socialização política. No fim das contas, melhorar a efetividade de uma prática implica conhecer o regime de ação (THÉVENOT, 2001) que governa essa mesma prática.

\section{Metodologia}

A estratégia metodológica seguida procurou conhecer os quadros de envolvimento normativo dos estudantes do ensino médio público português. Com o objetivo de ser fiel ao quadro analítico delineado no ponto anterior e de molde a captar o juízo prático dos atores, recorremos ao instrumento metodológico do questionário por cenários. O instrumento, apesar de pouco utilizado nas Ciências Sociais, apresenta um forte potencial para desenvolver uma "pesquisa interessante" (RAMIREZ et al., 2015). O mesmo justifica-se como adequado para dar conta das expetativas recíprocas, tradiçôes e constrangimentos, que pesam sobre os julgamentos dos atores. Ele permite, ainda, captar os aspetos mais situacionais e comportamentais envolvidos na experiência dos estudantes em cada situaçáo. Para a elaboraçáo do questionário, foram construídas pequenas narrativas, perfazendo situaçôes realistas, próximas ao cotidiano dos estudantes, caracterizadas por uma pluralidade de valores em tensão, à semelhança de dilemas morais. Foi pedido aos atores que escolhessem, dentro das hipóteses apresentadas, aquela que mobilizasse um curso de ação considerado mais justo ou conveniente (THÉVENOT, 1990). Em seguida, foi-lhes solicitada uma justificação para a opção escolhida.

Foram selecionadas três escolas da Grande Lisboa, socialmente contrastantes, consistindo a amostra em 726 inquiridos do $10^{\circ}$ e $12^{\circ}$ anos de escolaridade (à entrada e à saída do ensino médio). Recolhidas as autorizaçóes dos encarregados de educação dos estudantes, os questionários foram implementados em sede de sala de aula, nas escolas.

Posteriormente à recolha da informação, procedeu-se à categorização e codificação das justificaçôes, segundo uma matriz de significados e de motivos. Essa operação consistiu em uma análise gramatical do material recolhido. A análise gramatical, desenvolvida já em outro artigo (CAETANO; MENDES, 2014), baseia-se nos pressupostos teleológicos da ação aristotélicos e nos pressupostos da gramaticalidade da língua defendidos por Wittgenstein (SOULEZ, 2004), pelos quais, para praticar a ação correta, a exemplo do uso correto da língua, basta viver 
e agir em uma comunidade de praticantes. A análise gramatical da ação permitenos aceder às significações das açôes contidas nas justificações, a partir das suas finalidades e das suas razōes (RICOEUR, 1990).

\section{Os cenários}

Os cenários elaborados tinham por finalidade descrever as expectativas recíprocas dos estudantes em duas situações pautadas por relaçôes de subordinação: na escola e em uma empresa. Nessas, colocamos os sentidos de responsabilidade dos estudantes à prova.

O primeiro cenário relata-nos uma situação de perturbação da normalidade do funcionamento escolar, na qual uma representante da autoridade na escola, na pessoa da subdiretora, surpreende alguns alunos retardatários que faziam barulho no corredor (dentro do horário letivo), quando seria presumível encontrarem-se já dentro da sala de aula. Acontece que o docente da turma tinha estabelecido, no início do ano letivo, um acordo, uma espécie de pacto, com os seus alunos, pelo qual eles se beneficiariam do privilégio de um retardamento de 5 minutos iniciais na chegada à sala de aula (sem a respectiva sanção por atraso). Ora, a subdiretora, desconhecendo o acordo, repreendeu os infratores, entrou no espaço da sala de aula e exigiu do docente a marcação das respetivas faltas.

As hipóteses apresentadas aos estudantes foram as seguintes (o professor deverá): proceder de acordo com as indicaçóes da subdiretora; continuar a proceder da mesma forma que antes, cumprindo o acordo com os alunos e encarrega o delegado de turma da responsabilidade de verificar que os alunos não fazem barulho nos corredores antes de entrar na sala; repreender os alunos que estavam fazendo barulho, para além de lhes marcar falta; fazer um novo acordo com os alunos, acabando a aula cinco minutos mais cedo; relatar à subdiretora o acordo que fizera com os alunos.

No segundo cenário, encontramo-nos em uma situação em que um grupo de empregados de uma empresa comunica entre si, sob um tom crítico e por meio da rede social Facebook, açôes realizadas pela direção. Essa, tendo conhecimento, imediatamente convoca uma reuniáo com todos os trabalhadores anunciando a entrada em vigor de um novo regulamento da empresa, em que se proíbe os comentários de natureza pessoal acerca da empresa.

Nesse cenário, as hipóteses apresentadas aos estudantes foram as seguintes: concordo com o novo regulamento, uma vez que ao escrever opinióes pessoais sobre a empresa, posso colocar a imagem da instituição em causa; não concordo com o novo regulamento, pois apesar de achar que não é correto escrever opiniōes pessoais sobre a empresa, isso é algo que tem a ver com o bom senso e a responsabilidade de cada um; não concordo, pois penso que não há problema nenhum 
em escrever opinióes pessoais no Facebook, a atitude da empresa viola a liberdade de expressão; não concordo, pois penso que as nossas opinióes pessoais e a nossa postura no trabalho são aspectos perfeitamente separados; concordo que não se deva escrever opinióes pessoais sobre a empresa, embora pense que a direção da empresa deveria ter falado primeiro com os trabalhadores em causa.

Isto posto, solicitava-se aos inquiridos que assinalassem a opção mais correta correspondente à atitude a tomar por parte do docente, no primeiro cenário, ou que tomassem posição relativamente à atuação da administração da empresa, no segundo cenário.

\section{Resultados}

Os primeiros resultados mostram que a maioria dos estudantes tende a ajuizar as duas situaçôes preferencialmente orientados por uma ética prudencial, não imperativa, do que por uma ética da responsabilidade» weberiana (WEBER, 2003). Eles nos sugerem claramente uma mobilização da vulnerabilidade e da exposição, reveladora, por certo, do modo como os estudantes pressentem a sua condição. $\mathrm{O}$ que está em jogo, quando a maioria não opta por um envolvimento segundo a ética da responsabilidade, não é tanto a demonstração de uma atitude refratária ao reconhecimento da autoridade, mas uma demonstração da sua condição de vulnerabilidade. Essa vulnerabilidade diz respeito, sobretudo, à sua dependência face à ordem hierárquica e burocrático-legal que as interações (escolares e laborais) fazem privilegiar.

Em uma primeira análise, detecta-se claramente que o conteúdo das justificaçôes pode ser alinhado segundo uma orientação teleológica. Existe, na verdade, uma competição de bens gramaticais, os quais se constituem como uma manifestação de uma "competição de programas narrativos" (RICOEUR, 1990, p. 193). Estão em jogo diferentes horizontes de práticas, à partida conflitantes entre si. A perseguição de um bem implica mobilizar uma gramática do agir, seguir as regras dessa gramática, em detrimento das outras. Encontramos claramente a presença de quatro bens gramaticais. Um desses bens é a liberdade, sendo os restantes: a confiança, a disciplina e o coletivo. O Quadro 1 mostranos o conjunto de todas as orientaçôes normativas mobilizadas pelos estudantes, podendo-se observar que $12 \%$ dos estudantes optaram por não responder no cenário do Facebook. Ainda que os bens gramaticais sejam os mesmos para os dois cenários, dadas as situaçōes serem diferentes, os bens gramaticais não devem ser vistos como equivalentes, mas apenas o seu significado geral teleológico ${ }^{1}$. Assim, o significado da confiança no cenário da sala de aula não se equivale ao significado da confiança no cenário do Facebook, contudo, pode-se retirar dos mesmos o significado geral da orientação pela confiança. 
Se atentarmos na distribuição percentual dos bens gramaticais pelos cenários, constatamos que, no cenário da sala de aula, o bem gramatical da confiança, particularmente o laço de confiança entre professor e estudantes, destaca-se de todas as possibilidades normativas. De seguida, vem o bem gramatical da disciplina, mormente as regras e o estatuto.

No cenário do Facebook, surge em primeiro lugar o bem gramatical da liberdade, sobretudo a separação da vida profissional de outras dimensões da vida, em nome da liberdade de expressão, logo seguido do bem gramatical da confiança, mormente do que designaremos por pedagogia e compreensão da intenção.

O deslastre normativo das justificaçōes deixa a descoberto uma pluralidade de perspectivas, mas sobretudo a vulnerabilidade dos estudantes face à sua condição de subordinação ou, ainda, sobretudo no caso do cenário do Facebook, uma falta de familiaridade com o mundo laboral e consequente maior dificuldade de antevisão das consequências futuras desencadeadas por uma possível ação. O Quadro 2 resume os significados teleológicos presentes nas justificações.

\section{A vulnerabilidade como condição do envolvimento na responsabilidade}

O questionário por cenários possibilitou captar os juízos práticos dos estudantes quanto aos cursos de ação alternativos que expressam os seus envolvimentos e compromissos em uma dada situação, caraterizada essencialmente por relações de dependência e de subordinação. O que os envolvimentos nos mostram é a orientaçáo dos mesmos para um bem gramatical: a confiança, a liberdade, a disciplina ou o coletivo. A teleologia da atividade orientada para uma finalidade deve-se ao seu caráter normativo - regras e normas que governam as práticas. Essas práticas agenciam uma determinada trajetória de conduta, segundo um dado regime de envolvimento (THÉVENOT, 2014).

Os bens gramaticais em presença nos revelam a pluralidade dos valores em presença e a não comensurabilidade dos mesmos, pelo que os possíveis conflitos entre os valores aumentam os riscos desses valores ou bens não pode-

\section{Quadro 1}

A distribuição dos bens gramaticais nos dois cenários.

\begin{tabular}{|l|c|c|c|c|c|c|c|c|c|c|}
\hline \multirow{2}{*}{$\begin{array}{l}\text { Bens } \\
\text { gramaticais }\end{array}$} & \multicolumn{2}{|c|}{ Liberdade } & \multicolumn{2}{|c|}{ Confiança } & \multicolumn{2}{c|}{ Disciplina } & \multicolumn{2}{c|}{ Coletivo } & \multicolumn{2}{c|}{ Total } \\
\cline { 2 - 11 } & $\mathbf{n}$ & $\mathbf{\%}$ & $\mathbf{n}$ & $\mathbf{\%}$ & $\mathbf{n}$ & $\mathbf{\%}$ & $\mathbf{n}$ & $\mathbf{\%}$ & $\mathbf{n}$ & $\%$ \\
\hline $\begin{array}{l}\text { Cenário } \\
\text { sala de aula }\end{array}$ & 137 & 21,92 & 279 & 44,64 & 199 & 31,84 & 2 & 1,60 & 625 & 100,00 \\
\hline $\begin{array}{l}\text { Cenário } \\
\text { Facebook }\end{array}$ & 218 & 30,00 & 179 & 24,70 & 130 & 17,90 & 112 & 15,40 & 639 & 88,00 \\
\hline
\end{tabular}


rem ser todos alcançados. Mas, não só os valores são plurais, como também os envolvimentos nos valores são plurais. Assim, por exemplo, o bem da liberdade poderá constituir a finalidade de certo conjunto de açóes, mas o modo como se participa ou se envolve nesse conjunto de açóes pode ser consideravelmente diferente: defender o valor da liberdade de expressão por si mesma representa um compromisso de outra ordem relativamente à exigência do direito da separação entre uma vida profissional e uma vida privada ou pública; enquanto o primeiro comprometimento se refere a um valor, o segundo se faz mediante $\mathrm{o}$ acionamento de um direito.

No que concerne especificamente aos cenários aqui expostos, ressaltam da análise gramatical dois importantes pontos: a demanda de maior flexibilidade nas interaçóes, no primeiro cenário; e a demanda de mais informação sobre as interaçôes, no cenário do Facebook. No primeiro caso, as tarefas normativas de gestão de um grupo de estudantes emergem como fulcrais na profissão docente. Nesse senti-

\section{Quadro 2}

Análise semântica dos bens gramaticais nos dois cenários.

\begin{tabular}{|c|c|c|c|c|}
\hline $\begin{array}{l}\text { Bens } \\
\text { gramaticais }\end{array}$ & Liberdade & Confiança & Disciplina & Coletivo \\
\hline $\begin{array}{l}\text { Cenário sala } \\
\text { de aula }\end{array}$ & $\begin{array}{c}\text { Acordo deve } \\
\text { prevalecer, } \\
\text { pois é } \\
\text { VANTAJOSO } \\
\text { e do } \\
\text { AGRADO dos } \\
\text { estudantes. } \\
\text { Voltar atrás } \\
\text { seria uma } \\
\text { TRAIÇÃO } \\
\text { por parte do } \\
\text { professor. }\end{array}$ & $\begin{array}{c}\text { O professor } \\
\text { deve ser justo e } \\
\text { SINCERO, por } \\
\text { isso deve relatar } \\
\text { à subdiretora o } \\
\text { acordo que fizera. } \\
\text { Se o professor } \\
\text { contar tudo, } \\
\text { pode ser que } \\
\text { assim a diretora } \\
\text { COMPREENDA } \\
\text { e concorde com o } \\
\text { acordo. }\end{array}$ & $\begin{array}{c}\text { O professor deve } \\
\text { OBEDECER a alguém } \\
\text { hierarquicamente superior. } \\
\text { O professor deveria ter } \\
\text { SEGUIDO AS REGRAS } \\
\text { da escola. }\end{array}$ & $\begin{array}{c}\text { As regras têm } \\
\text { de ser IGUAIS } \\
\text { para todos } \\
\text { os alunos da } \\
\text { escola e todos } \\
\text { os alunos } \\
\text { devem ser } \\
\text { tratados por } \\
\text { igual. }\end{array}$ \\
\hline $\begin{array}{l}\text { Cenário } \\
\text { Facebook }\end{array}$ & $\begin{array}{c}\text { Defesa da } \\
\text { LIBERDADE } \\
\text { DE } \\
\text { EXPRESSÃO. } \\
\text { DIREITO de } \\
\text { SEPARAÇÃO } \\
\text { entre o trabalho } \\
\text { e as opinióes } \\
\text { pessoais. }\end{array}$ & $\begin{array}{l}\text { A reunião é } \\
\text { escusada, pois } \\
\text { os trabalhadores } \\
\text { NÃO SABIAM, } \\
\text { pelo que o melhor } \\
\text { seria o diretor } \\
\text { FALAR com os } \\
\text { trabalhadores } \\
\text { em causa para } \\
\text { eles mudarem } \\
\text { de atitude e } \\
\text { EXPLICAR- } \\
\text { LHES a gravidade } \\
\text { da situaçáo. }\end{array}$ & $\begin{array}{l}\text { PRUDÊNCIA, já que está } \\
\text { em causa o próprio emprego. } \\
\text { A comunicação } \\
\text { entre funcionários e } \\
\text { direção deve ser feita } \\
\text { HIERARQUICAMENTE. }\end{array}$ & $\begin{array}{c}\text { Mesmo que os } \\
\text { procedimentos } \\
\text { da direçáo } \\
\text { náo sejam os } \\
\text { mais corretos, } \\
\text { devemos } \\
\text { VELAR PELA } \\
\text { EMPRESA. }\end{array}$ \\
\hline
\end{tabular}


do, os problemas de indisciplina não podem ser encarados apenas como uma consequência do declínio da autoridade institucional, porquanto, os mesmos eventualmente requererão uma combinação tática de envolvimentos do docente. Como nos confessa um aluno: "é preciso arranjar um intermédio" entre a simpatia de "fechar os olhos" à pontualidade dos estudantes e a rigidez disciplinar mobilizada por ação dos professores. O "intermédio" afasta-se da intransigência, mas define regras e limites de partida. A aplicação prática desses princípios de conduta deve ser realizada de modo firme e geral.

No segundo caso, o espaço de experiência social e política alarga-se consideravelmente: do espaço confinado de uma escola que se rege por uma ordem legal-burocrática, ao espaço tecnopolítico das redes sociais, um espaço de fronteira, cujo estatuto jurídico encontra-se ainda paulatinamente a definir-se. $\mathrm{O}$ que esse cenário coloca em evidência, para além de certa divisão entre aqueles que defendem a liberdade de expressão e aqueles que optam por uma ética prudencial, com receio de serem prejudicados ou da empresa poder sair prejudicada, é a desarmante vulnerabilidade dos estudantes perante essa ordem de interação. De fato, a trajetória da confiança, ao contrário do direito ou da prudência, remete-nos para um envolvimento pautado pela pedagogização da comunicação e pelas relaçóes face-a-face, de uma demanda por consideração pela pessoa em termos individuais e singularizantes (OLIVEIRA, 2002). As seguintes justificaçóes são suficientemente elucidativas: "Era preciso avisar os trabalhadores antes de eles escreverem sobre a empresa"; "Não se deve escrever opiniōes pessoais sobre a empresa, porque pode dar mau aspeto à mesma, mas a direção da empresa deveria ter falado primeiro com os trabalhadores, porque se não os trabalhadores não podem confiar na direção".

A necessidade sentida, por alguns estudantes da empresa, de avisar primeiro os trabalhadores e desse aviso ocorrer sob uma forma singularizante sublinha o envolvimento de subjetivação pelo qual esses estudantes se deixam mobilizar. Com efeito, parece denotar-se aqui a presença de uma componente de justiça denominada de justiça informacional e interpessoal (KAZEMI, 2016), a qual produz efeito na motivação dos estudantes em agir segundo determinados objetivos desejados.

A análise gramatical nos permitiu assim reconhecer a existência de uma multiplicidade de bens gramaticais e de envolvimentos na responsabilidade, bem como uma pluralidade de dimensóes da justiça: uma justiça cívica, uma justiça informacional, uma justiça subjetiva, ancorada na compreensão mútua. As gramáticas da confiança nos revelam não apenas a colocação à prova da vulnerabilidade dos estudantes, mas também a pluralidade de gramáticas políticas disponíveis e não comensuráveis a uma ética da obediência ou da responsabilidade. Na verdade, e socorrendo-nos mais uma vez das palavras de Nussbaum (2001, p. XXX), "a vulnerabilidade constitui um pano de fundo necessário de certos bens genuinamente humanos (a ação política, o amor, a amizade)". 


\section{Conclusão}

A pesquisa efetuada assentou em um desenho de investigação visando explorar os significados das expectativas recíprocas dos estudantes do ensino secundário português em situaçôes próximas da realidade dos mesmos, caracterizadas por relaçóes de subordinação. Com o auxílio do instrumento metodológico do questionário por cenários e dos procedimentos de análise gramatical, pudemos extrair esses significados, os quais "dependem tipicamente das referências indexadas à situação compartilhada, das referências elípticas de situações anteriores e de preferências projetivas para futuros juízos" (STAHL, 2005, p. 8).

Essa opção teórico-metodológica elege o contexto normativo como unidade principal de análise, incorpora a contingência da ação e considera os estudantes como atores táticos, flexíveis, capazes de gerir e de se ajustar a contextos diferenciados, envolvendo-se nas várias situaçóes. Ao se envolverem nas situaçôes, os estudantes, inseridos em uma ou mais atividades, experienciam trajetórias normativas direcionadas para determinados bens - bens gramaticais. Essas trajetórias constituem-se como gramáticas de ação.

Os resultados das justificaçóes dos questionários revelam a mobilização de uma pluralidade de gramáticas na responsabilidade por parte dos estudantes. Entre a disciplina ou o coletivo e a liberdade, cujos significados permanecem indexicalizados, emerge a gramática da confiança, a qual coloca em evidência a vulnerabilidade dos atores nas situaçôes. Essa vulnerabilidade poderia estar diretamente relacionada à existência de falhas nos arranjos políticos (NUSSBAUM, 2001, p.XXX), contudo, nos casos investigados, ela emerge, sobretudo, enquanto condição de exposição dos atores à imputação de responsabilidades. No primeiro dos cenários, os estudantes apelam à intenção e à compreensão da situação por parte do superior hierárquico, ao passo que, no segundo cenário analisado, os estudantes apelam para um reconhecimento de si enquanto seres singulares e por uma pedagogização da situação. $\mathrm{O}$ reconhecimento singularizante é importante enquanto motivaçáo para agir em uma direção desejável. Nesse sentido, à justificaçáo (BOLTANSKI; THÉVENOT, 1991), acrescem as demandas de compreensão e de informação como conceitos com significado político. A justificação, como forma de provar o justo em sua generalidade, não dá conta de outras formas políticas de justeza, tais como aquelas expressas pelas ideias de compreensão e de informação enquanto demandas do justo, e é por isso mesmo que poderemos falar de uma socialização política no plural, e não apenas centrada nas capacidades argumentativas dos atores. Tanto a compreensão como a informação enquanto dimensōes do justo nos permitem lançar luz sobre a vulnerabilidade dos estudantes. As formas de fazer face a essas demandas surgem expressas, por exemplo, em alguns dos tipos mais comuns de procedimentos e garantias desenvolvidos nas modernas sociedades ocidentais, como, por exemplo, quando se apela para a necessidade de ouvir os estudantes, procurando compreendê-los; ou ainda na 
generalização dos procedimentos "garantistas" do consentimento informado, táo em voga nas nossas sociedades liberais.

$\mathrm{Na}$ verdade, a problemática da vulnerabilidade na cidadania tem sido de certo modo obscurecida pelo destaque dado às virtudes cívicas enquanto marcas da excelência, porém, excelência e vulnerabilidade coexistem, como acontece no esboço da teoria moral aristotélica em Ética a Nicómaco (ARISTÓTELES, 322 a.C./2009), e não devem ser vistas, portanto, de modo binário ou exclusivo. A vulnerabilidade é, inclusivamente, uma das condições da excelência, pois o que se opóe à vulnerabilidade é precisamente a autossuficiência (NUSSBAUM, 2001, p. 312). A vulnerabilidade representa a expressão humana das nossas múltiplas dependências: físicas, biológicas, psicológicas, sociais e políticas.

Potenciar uma socialização política plural implica, desse modo, a recusa da primazia da universalidade e do intelectualismo no juízo crítico dos atores relativamente às suas capacidades responsivas e criativas. Ela implica, consequentemente, da escola, enquanto instância socializadora privilegiada, uma abordagem multipolar, não apenas centrada na transmissáo de conhecimentos e no desenvolvimento das competências críticas de argumentação, mas também na familiarização dos estudantes com várias ordens de interação, na promoção de projetos específicos onde os mesmos possam testar e desenvolver as suas capacidades, e na multiplicação de espaços de encontro potencializadores de trocas de experiências e de informação.

\section{Nota}

1. O significado geral teleológico da ação representa aqui a recuperação de um conceito caro à tradiçẫo da filosofia política e moral pré-moderna. Segundo Thévenot (2001, p. 6), "com a sua ruptura inaugural da filosofia política e moral, a Sociologia distanciou-se a si mesma da ideia de bem. Como resultado, a Sociologia tende a desconfiar de tais ideias reminiscentes da filosofia política e moral da qual os sociólogos acreditam ter-se libertado". O significado teleológico representa assim "o elemento moral em prática que enforma o processo que governa os envolvimentos dos agentes" (THÉVENOT, 2001, p. 2). E é nesse sentido que, para Thévenot (2001, p. 5), os regimes de envolvimento são sociais: "eles orientam o agente na sua conduta e determinam a maneira como os agentes 'sustém' esta mesma conduta. Este elemento pode ser chamado de 'fazer sentido de', se quisermos entender com isto aquilo que se relaciona com o significado, a linguagem e a compreensão".

\section{Referências}

ARISTÓTELES. Ética a Nicómaco. Tradução de António de Castro Caeiro. Lisboa: Quetzal Editores, 2009.

BOLTANSKI, L.; THÉVENOT, L. De la justification: les économies de la grandeur. Paris: Gallimard, 1991. 
CAETANO, P.; MENDES, M. Shaping ways of managing diversity in Portuguese schools from the student's perspective. International Review of Sociology: Revue Internationale de Sociologie, v. 24, n. 2, p. 325-344, 2014.

CARR, W.; KEMMIS, S. Becoming critical: education, knowledge and action research. London: Falmer Press, 1986.

COMISSÃO DAS COMUNIDADES EUROPEIAS (CCE). Livro verde sobre a dimensão europeia na educação. Bruxelas, 1993.

DE CERTEAU, M. The practice of everyday life. Berkeley: University of California Press, 1988.

DIREÇÃO-GERAL DA EDUCAÇÃO (DGE). Educação para a cidadania - linhas orientadoras. Lisboa, 2013.

- Referencial dimensão europeia da educação para a educação pré-escolar, o ensino básico e o ensino secundário. Lisboa, 2015.

EKMAN, J.; AMNÅ, E. Political participation and civic engagement: towards a new typology. Human Affairs, v. 22, n. 3, p. 283-300, June 2012. DOI: 10.2478/s13374012-0024-1.

EUROPEAN COMMISSION (EC). Priorities of the programme for 2016. Eurydice Project. Disponível em: <https://eacea.ec.europa.eu/sites/eacea-site/files/priorities of the programme for 2016 5.pdf>. Acesso em: 3 jun. 2016:, 2016.

GIBSON, C.; LEVINE, P. (Coord.). The civic mission of schools. New York: Carnegie Corporation of New York/The Center for Information and Research on Civic Learning and Engagement, 2003. Disponível em: <http://civicyouth.org/PopUps/ CivicMissionofSchools.pdf>. Acesso em: 27 maio 2016.

KAZEMI, A. Examining the interplay of justice perceptions, motivation, and school achievement among secondary school students. Social Justice Research, v. 29, n. 1, p. 103118, mar. 2016. DOI: 10.1007/s11211-016-0261-2.

MOREIRA, C.; ROSAS, J.C.; LOBO, M.C. Programa de Ciência Politica - 12o ano. Lisboa: Ministério da Educação, 2006.

NUSSBAUM, M.C. The fragility of goodness: luck and ethics in Greek tragedy and philosophy. 2nd ed. Cambridge, Mass.: Cambridge University Press, 2001.

OLIVEIRA, L.R.C. Direito legal e insulto moral: dilemas da cidadania no Brasil, Quebec e EUA. Rio de Janeiro: Relume Dumará, 2002.

O'NEILL, B. Indifferent or just different? The political and civic engagement of young people in Canada: charting the course for youth civic and political participation. CPRN Research Report. Ottawa: Canadian Policy Research Networks, 2007. Disponível em: <http://www.cprn.org/documents/48504 EN.pdf>. Acesso em: 27 maio 2016.

RAMIREZ, R. et al. Scenarios as a scholarly methodology to produce "interesting research". Futures, v. 71, p. 70-87, Aug. 2015.

RESENDE, J.M. A sociedade contra a escola? A socialização política escolar num contexto de incerteza. Lisboa: Instituto Piaget, 2010. 
RIBEIRO, N.; NEVES, T; MENEZES, I. Educação para a cidadania em Portugal: contributos para analisar a sua evolução no currículo escolar português. Currículo sem Fronteiras, Porto, v. 14, n. 3, p. 12-31, set./dez. 2014.

RICOEUR, P. Soi-même comme un autre. Paris: Seuil, 1990.

SOULEZ, A. Wittgenstein et le tournant grammatical. Paris: PUF, 2004.

STAHL, G.; KOSCHMANN, T.; SUTHERS, D. Computer-supported collaborative learning: an historical perspective. In: SAWYER R.K. (Ed.), Cambridge handbook of the learning sciences. Cambridge, UK: Cambridge University Press, 2005. p. 409-426,

THÉVENOT, L. L'action qui convient. In: PHARO, P.; QUÉRÉ, L. (Éd.) Les formes de l'action. Paris: EHESS, 1990. p. 39-69.

Pragmatic regimes governing the engagement with the world. In: SCHATZKI, TR.; KNORR-CETINA, K.; SAVIGNY, E. (Ed.), The practice turn in contemporary theory. London: Routledge, 2001. p. 56-73..

. L 'action au pluriel: sociologie des régimes d'engagement. Paris: La Découverte, 2006.

Voicing concern and difference: from public spaces to commonplaces. European Journal of Cultural and Political Sociology, v. 1, n. 1, p. 7-34, May 2014.

U.S. DEPARTMENT OF EDUCATION (USDE). Advancing civic learning and engagement in democracy: a road map and call to action. Washington, D.C., 2012. Disponível em: <https://www.ed.gov/sites/default/files/road-map-call-to-action.pdf $>$. Acesso em: 19 maio 2016.

WEBER, M. Le savant et le politique: une nouvelle traduction. Tradução Catherine Colliot-Thélène. Paris: La Découverte, 2003.

Recebido em 29 de junho de 2016.

Aprovado em 14 de outubro de 2016. 